\title{
Novo modelo de governança: velhas estratégias de gestão das escolas estaduais de Santa Catarina
}

\section{New governance model: old management strategies for state schools in Santa Catarina}

\section{Nuevo modelo de gobernanza: viejas estrategias de gestión para las escuelas públicas de Santa Catarina}

\author{
Aline da Silva Serpa Marangoni ${ }^{1}$ \\ Oto João Petry ${ }^{1}$
}

DOI: http://dx.doi.org/10.20435/serie-estudos.v26i56.1436

\begin{abstract}
Resumo: O presente artigo tem o objetivo de explorar diferentes conceitos acerca dos termos governança, governação e governabilidade, inseridos em uma perspectiva de influência dos modos de gestão. Busca-se aqui apresentar conceitos influenciadores da gestão escolar, assim como contrapor à ideia de surgimento de um novo modelo de gestão das escolas estaduais de Santa Catarina (SC). Após a conceitualização desses termos, apresenta-se a organização escolar por meio da adesão a um modelo de governança com raízes na administração empresarial. Destacam-se, nas análises, diferentes interpretações do conceito de governança, sendo uma delas utilizada para representar o modo de gestão aplicado nas escolas estaduais de SC como um modelo participativo e democrático. Por fim, apresentam-se no artigo as legislações e os decretos que resultaram na implementação desse novo modelo, juntamente de uma breve análise de textos e da conjuntura em que ocorreu a implementação. Para as conclusões deste estudo, destaca-se que, apesar de a gestão escolar caminhar para rumos democráticos por meio de legislações e teorias, a prática ainda ocorre nos velhos moldes centralizados e hierárquicos, em que o novo modelo de governança nada mais é que a reestruturação da velha organização escolar.
\end{abstract}

Palavras-chave: gestão escolar; governança; democratização.

Abstract: This article aims to explore different concepts about the terms governance, governing, and governability, inserted in a perspective of the influence of management modes. We seek to present concepts that influence school management, as well as a counterpoint to the emergence idea of a new management model for state schools in Santa Catarina (SC). After conceptualizing these terms, the school organization is introduced through adherence to a governance model with roots in business administration. Different interpretations of the concept of governance stand out in the analyzes, one of which is used to represent the management model used by the state schools of SC as a participatory and democratic model. Finally, the article presents the laws and decrees

\footnotetext{
1 Universidade Federal da Fronteira Sul (UFFS), Chapecó, Santa Catarina, Brasil.
} 
that resulted in this new model implementation, together with a brief analysis of texts and the conjuncture in which the implementation occurred. For the conclusions of this study, we highlighted that despite school management moving towards democratic directions through legislation and theories, the practice still happens in the old centralized and hierarchical molds in which the new governance model is nothing more than the restructuring of the old one school organization.

Keywords: school management; governance; democratization..

Resumen: Este artículo tiene el objetivo de explorar diferentes conceptos sobre los términos gobernanza, gobernación y gobernabilidad, insertados en una perspectiva de influencia de los modos de gestión. Aquí se busca presentar conceptos que influyan en la gestión escolar, así como oponerse a la idea del surgimiento de un nuevo modelo de gestión para las escuelas estatales en Santa Catarina (SC). Después de conceptualizar estos términos, presentase la organización escolar mediante la adhesión a un modelo de gobierno con raíces en la administración de empresas. En el análisis, son destacados diferentes interpretaciones del concepto de gobernanza, una de las cuales se utiliza para representar el modo de gestión utilizado por las escuelas estatales en SC como un modelo participativo y democrático. Finalmente, se presenta en el artículo las leyes y decretos que dieron como resultado la implementación de este nuevo modelo, junto de un breve análisis de los textos y la situación en la que tuvo lugar la implementación. Para las conclusiones de este estudio, destacase que, aunque la gestión escolar avanza hacia direcciones democráticas a través de la legislación y las teorías, la práctica todavía ocurre en los viejos moldes centralizados y jerárquicos, en los que el nuevo modelo de gobernanza no es más que la reestructuración de la organización de la vieja escuela.

Palabras clave: gestión escolar; gobernanza; democratización.

\section{INTRODUÇÃO}

O termo governança vem sendo amplamente adotado nas políticas públicas para a gestão escolar. Trata-se de um conceito abrangente e que se caracteriza por meio da participação dos atores sociais e políticos, sendo utilizado para descrever um modelo de gestão com base nos princípios democráticos.

A organização da gestão escolar, por sua vez, vem passando por um processo de democratização, em que alguns princípios básicos, como autonomia e participação, ganham ênfase na implementação desse modelo. Ao contemplar a construção da escola democrática, Lima (2000, p. 42) ressalta que não é possível pensá-la sem "[...] a participação activa de professores e de alunos, mas cuja realização pressupõe a participação democrática de outros sectores e o exercício da cidadania crítica de outros actores, não sendo, portanto, obra que possa ser edificada sem ser em co-construção".

Porém, para efetivar uma gestão democrática, é necessário ainda rever e ressignificar os conceitos utilizados para conduzir a um processo de implementação 
na organização escolar. Ocorre, então, que se faz necessária uma distinção dos termos, que ainda vêm sendo utilizados para caracterizar a gestão escolar, mesmo com um viés mais empresarial, ou significações unilaterais referentes ao exercício do poder em uma dimensão mais estatal. Dessa forma, os conceitos de governabilidade e governação devem ser amplamente esclarecidos, a fim de que a intencionalidade na escolha por um ou outro não esteja associada à singularidade dos termos, levando à sua utilização equivocada na organização da gestão escolar.

Como objetivo principal do texto, busca-se explorar diferentes conceitos acerca dos termos governança, governação e governabilidade, inseridos em uma perspectiva de influência dos modos de gestão. Para contemplá-lo, a organização do artigo apresenta em sua primeira seção a conceituação do termo governança embasada em autores como Santos (1997), assim como em referências oriundas do Banco Mundial (1992 apud. SANTOS, 1997). Em sequência, a próxima seção destaca as diferentes conceituações para os termos governança, governabilidade e governação, incluindo autores como Rosenau (2000), Lourenço e Moreira (2014). A terceira seção apresenta como o conceito de governança está presente na organização escolar, de maneira a dialogar ou não com os princípios de uma gestão democrática. Para a quarta seção, autores como Gonçalves (2005) e Santos (1997) abordarão o modelo de governança com base em uma herança empresarial. E, por fim, a última seção apresenta as legislações e os decretos do estado de Santa Catarina (SC), que resultaram na implementação desse novo modelo, juntamente de uma breve análise de textos e da conjuntura em que ocorreu tal implementação.

\section{GOVERNANÇA: CONCEITOS DE UM NOVO MODELO DE GESTÃO}

Segundo Santos (1997), "o conceito [de governança] não se restringe, contudo, aos aspectos gerenciais e administrativos do Estado, tampouco ao funcionamento eficaz do aparelho de Estado"; esse conceito de governança refere-se a "padrões de articulação e cooperação entre atores sociais e políticos e arranjos institucionais que coordenam e regulam transações dentro e através das fronteiras do sistema econômico" (SANTOS, 1997, p. 341-2). Ou seja, ao mencionar os atores sociais e políticos como participantes desse modelo, ampliam-se os mecanismos tradicionais de articulação, incluindo, além de partidos políticos, outros grupos sociais informais, como as famílias, as comunidades, as associações diversas, entre outros. 
Os desafios do Brasil pós-Constituinte também perpassam pela conceituação de governabilidade e governança (governance), estas tratadas pela literatura como a relação entre o Estado, a economia, a sociedade e as políticas. Seguindo essa conceituação, destaca-se que os desafios têm se definido em áreas, como o ajuste da economia e a reforma do Estado - que não pode mais ser mínimo, tendo suas funções reorientadas. O resgate da dívida social faz parte também dos seus desafios, sendo descrito pela necessidade de um programa social de governo que possa compensar a desestabilização política que levou a uma injustiça social. O terceiro desafio compreende o enfrentamento dos desafios anteriores, mantendo-se a ordem democrática. Nesse caso, pode-se compreender o desafio como a construção de alianças políticas democráticas que sustentem o governo com qualidade democrática, inserido em um contexto de expansão de participação e diversificação das formas de representação. O debate contemporâneo sobre o novo Estado ${ }^{2}$ tem direcionado suas propostas às áreas políticas, sociais, organizacionais e gerenciais, buscando enfrentar os desafios e os dilemas que são apresentados nesse novo modelo (SANTOS, 1997).

O direcionamento aos termos governança e governabilidade segue uma lógica de reorganização do Estado, mas, além disso, é capaz de explicar os modelos de organização voltados a uma perspectiva democrática, que resultou em um novo termo: capacidade governativa (SANTOS, 1997).

Ao tratar a respeito da conceituação de cada um desses termos, tem-se que a governabilidade é vista por Santos (1997) como o funcionamento adequado dos sistemas políticos, o qual depende do equilíbrio da participação social e da atividade governamental, refletindo em políticas públicas adequadas a um contexto de democracias consolidadas. Outras análises realizadas acerca desses termos são

\footnotetext{
2 Enquanto em 1997 caminhava-se para redesenhar o papel do Estado sob uma perspectiva de expansão de políticas sociais e democráticas, vive-se em 2020 uma nova compreensão seguida de ações em curso que estão redirecionando o papel do Estado. Em meio à pandemia (oriunda do novo coronavírus) vivenciada pelo mundo desde 2020, presencia-se uma redefinição do papel do Estado. Enquanto países como China, Coreia, Alemanha, França, Espanha, Portugal, Reino Unido, podendo citar também, recentemente, os Estados Unidos da América, estão tomando medidas que refletem o papel e a preocupação dos Estados com sua população, maximizando medidas de prevenção e combate à pandemia, o Brasil encontra-se em outro direcionamento e não se sabe precisar qual configuração terá na saída dessa crise instalada, de modo a impulsionar a retomada econômica e social.
} 
apresentadas pelas agências de financiamento, em destaque o Banco Mundial (1992, p. 1 apud. SANTOS, 1997, p. 7, tradução nossa), com a seguinte definição de governance: "[...] o exercício da autoridade, controle, gestão, poder do governo. É a maneira pela qual o poder é exercido na gestão dos recursos econômicos e sociais de um país para o desenvolvimento".

Seguindo um viés de conceituação do termo governance, assim utilizado por muitos autores, apresenta-se como parte do estudo a definição de Melo (1995), que se refere ao termo como o

[...] modus operandi das políticas governamentais - que inclui, dentre outras, questões ligadas ao formato político institucional dos processos decisórios, à definição do mix apropriado do público/privado nas políticas, à participação e descentralização, aos mecanismos de financiamento das políticas e ao alcance global dos programas. (MELO, 1995, apud. SANTOS, 1997, p. 8).

Embora pareça mais voltado a questões de ordem financeira e econômica, o conceito não se restringe somente a aspectos administrativos, gerenciais e ao funcionamento eficaz do Estado.

Complementa Reis (1995), a respeito do termo "governabilidade", alertando para uma possível redução da terminologia quando se refere apenas à capacidade estatal de governar da máquina do Estado, voltando-se a mecanismos operacionais e ágeis em suas funções. Em sua crítica a essa simplificação do termo, o autor segue:

[...] há sociedade [...] e há política. E o desafio crucial reside na obtenção daquela forma específica de articulação do Estado com a sociedade na qual se reconheça que o problema da administração eficiente não pode ser dissociado do problema político, ou seja, do problema de garantir também a operação democrática do Estado. (REIS, 1995, p. 41)

É possível observar, a partir das conceituações utilizadas, que o conceito de governança ou governance ultrapassa o marco operacional para adentrar em questões relativas à articulação e cooperação entre os atores sociais e políticos. Inclui não apenas os mecanismos tradicionais de articulação de interesses, tais como os partidos políticos, mas também as redes sociais informais - como as famílias - e, ainda, as associações de diversos tipos.

Considerando a distinção e a aproximação dos termos governabilidade e governança, encontram-se as concepções estrutural-funcionalistas de capacidades 
do sistema (tradução nossa) e processo de conversão do sistema político. A capacidade (capability) do sistema político está ligada à sua performance, caracterizada por capacidade regulatória, extrativa, distributiva e responsiva, compreendendo um dos níveis de funcionamento do sistema político. O outro nível é considerado interno ao sistema e refere-se ao modo como demandas e apoios são transformados em decisões implementadas (SANTOS, 1997).

Conforme mencionado, outro termo utilizado por autores, como Malloy (1993), para descrever o conceito de "governabilidade", é o de "capacidade governativa", que, segundo ele, é compreendido como a capacidade de um sistema político em produzir políticas públicas visando resolver os problemas da sociedade; assim, de transformar a capacidade política de determinado conjunto de instituições e práticas políticas em potencial para definir, implementar e sustentar políticas. De acordo com Santos (1997), é possível adotar a definição de "capacidade governativa" se o sistema político for capaz de "(i) identificar problemas da sociedade e formular políticas públicas, isto é, oferecer soluções; e (ii) implementar as políticas formuladas, mobilizando para isso meios e recursos políticos, organizacionais e financeiros necessários" (SANTOS, 1997, p. 9).

Dessa forma, a capacidade governativa não seria avaliada apenas em observância aos resultados das políticas públicas governamentais, mas considerando a maneira como o governo exerce seu poder. Em suma, há duas questões que refletem a ideia central do termo. Primeiramente, compreendida por meio do pensamento de que uma boa governança é requisito fundamental para o desenvolvimento sustentado, englobando ao crescimento econômico equidade social e a efetivação dos direitos humanos (SANTOS, 1997). Em segundo, é verificada a questão dos procedimentos e práticas governamentais na execução de suas metas, incluindo aspectos que perpassam desde o formato institucional do processo decisório, a articulação entre público e privado na formulação de políticas públicas, até a participação de setores interessados ou das diferentes esferas do poder (DINIZ, 1995).

Como tal conceito permite uma análise ampla de sua expressão, acaba por facilitar seu uso equivocado, muitas vezes intencional e impreciso. Mesmo com aplicação em vários campos, com sentidos diferentes, o termo "governança" requer utilização cercada de cuidado e estudo analítico. Sabendo que o termo pode permear desde a esfera da economia, inserido na administração de empresas, é 
preciso compreender se cabe ao seu conceito outro direcionamento, voltado à dimensão política e participação social.

\section{GOVERNANÇA, GOVERNABILIDADE E GOVERNAÇÃO}

O termo "governar" significa "deter uma posição de força a partir da qual seja possível desempenhar uma função imediatamente associada ao poder de decidir e implementar decisões ou, ainda, de comandar e mandar nas pessoas" (NOGUEIRA, 2001, p. 99). Pode-se associá-lo a algo imposto sobre alguém ou um grupo que exerce o poder e assim detém a autonomia para decidir e executar sobre os demais.

Já os termos "governança" e "governabilidade" são mais completos e qualificativos, representando atribuições, qualidades, meios e processos, o que, muitas vezes, dificulta a distinção entre ambos.

O termo "governança" tem um caráter mais amplo: pode englobar questões referentes também à governabilidade, mas vai além, como apresentado anteriormente; envolve a sociedade como um todo e não apenas as relações de Estado. Operando em um plano mais amplo, contempla desde os aspectos administrativos e gerenciais do Estado até suas políticas públicas e a relação que estas têm com a sociedade e os direitos humanos, voltando-se a questões de equidade e participação social.

Por sua vez, "governabilidade" refere-se mais à dimensão estatal do exercício do poder. Diz respeito às "condições sistêmicas e institucionais sob as quais se dá o exercício do poder, tais como as características do sistema político, a forma de governo, as relações entre os Poderes, o sistema de intermediação de interesses" (SANTOS, 1997, p. 342). A distinção ocorre ainda na medida em que o termo "governabilidade" refere-se à arquitetura institucional, enquanto "governança" está ligado à performance dos atores e sua capacidade no exercício da autoridade política (SANTOS, 1997).

Ao se analisar, então, a distinção realizada entre "governança" e "governabilidade", passa-se a considerar que "governança não é o mesmo que governo" (ROSENAU, 2000, p. 15). Ainda, o

[...] governo sugere atividades sustentadas por uma autoridade formal, pelo poder de polícia que garante a implementação das políticas devidamente instituídas, enquanto governança refere-se a atividades apoiadas em 
objetivos comuns, que podem ou não derivar de responsabilidades legais e formalmente prescritas e não dependem, necessariamente, do poder de polícia para que sejam aceitas e vençam resistências. [...] governança é um fenômeno mais amplo que governo; abrange as instituições governamentais, mas implica também mecanismos informais, de caráter não-governamental, que fazem com que as pessoas e as organizações dentro da sua área de atuação tenham uma conduta determinada, satisfaçam suas necessidades e respondam às suas demandas. (ROSENAU, 2000, p. 15-6).

Dessa forma, é no contexto social que ocorrem as disputas e delas resultam as normas que regularão os conflitos. Assim, a governança traz ao cenário a participação ativa dos setores e atores, ampliando as contribuições e opiniões capazes de influir nos resultados, seja no campo das políticas públicas, na regulação internacional, seja no campo estrito da produção e revisão de normas.

À medida que se faz presente em fatores como esses de representação social, a governança vai construindo sua legitimidade. É necessário, portanto, em uma democracia, que haja concorrências dos governantes e dos cidadãos e suas organizações, para formular e aplicar políticas que correspondam equilibradamente ao que a sociedade espera do governo. Todavia a governança não é a ação isolada da sociedade civil, tampouco a do Estado; ao contrário, o conceito compreende a ação conjunta entre Estado e sociedade na busca por soluções e resultados para problemas e questões comuns. "Mas é inegável que o surgimento dos atores não estatais é central para o desenvolvimento da ideia e da prática da governança [...]" (GONÇALVES, 2005, p. 14).

O mesmo se amplia na diferenciação entre "governança" e "governação": esta representa uma linha mais instrumental, visando "[...] o cumprimento de objetivos ou fins concretos, mesmo que de modo mais participado, afastando-se assim da forma autoritária de 'mando e controle'" (LOURENÇO; MOREIRA, 2014, p. 26). A primeira, por sua vez, é mais cívico-política, centrada nas questões dos meios, na primazia de valores abstratos.

Amplia-se a distinção entre "governança" e "governação" com base na assertiva de Lourenço e Moreira (2014):

Na primeira, a autoridade continuaria a basear-se, embora de forma mais branda e democrática, em "ordens" ou diretrizes a cumprir, ainda que atendendo aos interesses dos cidadãos e fazendo uso de mecanismos de mercado. Já na segunda a autoridade assentaria no primado do Direito, não 
da legislação. Ou seja, no respeito pelas regras de jogo, sem condescendência por quaisquer formas de hedonismo político, e, por isso, sem propensão à corrupção da sociedade civil por parte do Estado. (LOURENÇO; MOREIRA, 2014, p. 26)

Por meio das diferenças e similaridades estabelecidas no decorrer desta seção, optou-se, durante a realização deste trabalho, pela utilização do termo "governança", por contemplar, conforme descrevem Lourenço e Moreira (2014), sobretudo as relações sociais e os interesses dos cidadãos diante das políticas públicas educacionais, abrindo espaços para um estudo mais detalhado de gestão, que aos poucos vem sendo implementado nas escolas estaduais de Santa Catarina.

Dessa forma, não se poderia deixar de justificar tal escolha pelo termo adequado às propostas de trabalho da pesquisadora, e estas se justificam por meio da conceituação obtida em cada um dos termos que se direcionam ao entorno da temática escolhida. Na próxima seção, apresenta-se o termo "governança", inserido em uma perspectiva democrática de organização escolar.

\section{GOVERNANÇA E DEMOCRACIA NA ORGANIZAÇÃO ESCOLAR}

Quando se adentra na matéria da organização escolar, depara-se com questões como democracia e práticas pedagógicas democráticas. Por sua vez, não há como falar em pedagogia democrática sem mencionar Freire (1967), que, em uma de suas obras, Educação como prática de liberdade, trata da ação político-educativa que se desenvolveria nas três décadas seguintes. Em consonância à obra citada, Weffort (1967, p. 5) realiza um importante estudo introdutório destacando a "liberdade e a participação livre e crítica dos educandos", atribuindo sentido à prática educativa proposta por Freire. Segundo Lima (2000, p. 32, grifo do autor), essa é "[...] uma proposta de pedagogia democrática, de educação para e pela democracia, através de práticas dialógicas e anti-autoritárias e do exercício da participação, contra a passividade e para a decisão". Nas palavras de Freire (1967, p. 88), "uma educação para a decisão, para a responsabilidade social e política".

A proposta da aprendizagem da democracia pela prática da participação ganha significado por meio do seu exercício e de sua própria existência, conforme aponta Lima (2000), rejeitando as teorias elitistas e opondo-se a perspectivas formalistas subordinadas a uma liderança competitiva ou de caráter burocrático. O ponto principal dessa proposta é descrito por Freire (1967, p. 183), quando 
coloca que "a liderança não pode pensar sem as massas, nem para elas, mas com elas". É nesse viés que a democracia como prática da liberdade, juntamente do processo de aprendizado democrático, poderá vir a fortalecer as instituições e, assim, melhorar a democracia. Para isso, a organização democrática necessita ser falada, vivida e afirmada por meio da ação, de forma que

Ninguém vive plenamente a democracia nem tampouco a ajuda a crescer, primeiro, se é interditado no seu direito de falar, de ter voz, de fazer o seu discurso crítico; segundo, se não se engaja, de uma ou de outra forma, na briga em defesa desse direito, que, no fundo, é o direito também a atuar. (FREIRE, 1967, p. 88).

Seguindo essas reflexões acerca do papel que a instituição escolar exerce na construção da democracia, estabelecem-se críticas à escola burocrática, pelo fato de ser contrária à ação participativa, social e cultural, fortalecendo a sociedade civil no comando da res-pública. Desse modo, a democratização da escola pública torna-se um elemento crucial, sendo fator de mudança, e não apenas resultado mecânico da transformação da sociedade global. É, de certo modo, assumida como espaço de educação, participação e cidadania, com olhar crítico voltado à construção da esfera pública democrática.

Visto que esse é um processo envolvendo diferentes agentes sociais, poderá ocorrer na prática somente se houver uma "real participação da comunidade de pais e de representantes de movimentos populares na vida inteira das escolas" (FREIRE, 1991, p. 47-8), com a participação e voz dos educadores exercendo sua liberdade docente de maneira democrática e, ainda, por meio do poder de decisão conferido à escola, que levará a sua autonomia e liberdade. Como se percebe, a democratização da escola não se caracteriza apenas como um problema técnico-pedagógico, ao contrário, envolve também interesses e relações de poder entre atores escolares, algumas vezes contraditórios, mas sempre plurais, refletindo no projeto-político-educativo e no modo como será visto pela sociedade. Compreende-se aqui a assertiva de que não há neutralidade nos ideais instituídos pela educação: ou ela será domesticada ou será democrática (LIMA, 2000).

A luta constante por uma escola pública democrática implicará a progressiva inserção comunitária, buscando transformá-la em espaço ampliador da cultura popular e de organização política das classes populares. Observa-se que o que se propõe aqui é a legitimação de formas de governação democrática e 
de participação social ativa na tomada de decisões, não a retirada do Estado da administração, o abandono da escola pública, ou mesmo sua privatização. O caminho a ser percorrido é outro, voltado à

[...] governação democrática e participativa da escola, única e autónoma, integrada numa administração pública descentralizada (não uniforme nem hiper-regulamentadora), configura uma "escola-cidadã", uma só escola que só sendo autónoma poderá vir a ser uma escola para todos. (GADOTTI, 1992 apud. LIMA, 2000, p. 44).

Por fim, compreende-se que a democratização da escola, nas palavras de Lima (2000), vai além da democratização de suas estruturas organizacionais e de gestão, da eleição de gestores ou outros responsáveis; ela é dependente do sucesso escolar dos alunos, da pedagogia, do currículo e da avaliação, da organização do trabalho, da manifestação cívica e sociocultural da comunidade, representando, entre outros, elementos fundamentais para uma governação democrática.

Nesse sentido, é possível afirmar que "governança" e "democracia" são dois conceitos fundamentais na organização e estrutura escolar, visando à autonomia e liberdade da escola, à participação da comunidade e ao desenvolvimento de práticas inclusivas da realidade social. Dessa forma, a busca pela reestruturação escolar deve estar inteiramente amparada pela legislação e participação social, para dar o suporte necessário às estruturas implementadoras desse processo.

\section{O OUTRO LADO DESSE NOVO MODELO DE GOVERNANÇA: A HERANÇA EMPRESARIAL}

Destaca-se, no início desta seção, que é necessário precisar e direcionar o significado do conceito governança ao contexto em que é inserido, pois sua aplicabilidade pode ocorrer em diferentes campos, com sentidos diferentes - pode-se destacar a "governança corporativa", amplamente vinculada à administração de empresas.

Segundo o Instituto Brasileiro de Governança Corporativa (apud GONÇALVES, 2005, p. 2), "Governança Corporativa são as práticas e os relacionamentos entre os Acionistas/Cotistas, Conselho de Administração, Diretoria, Auditoria Independente

e Conselho Fiscal, com a finalidade de otimizar o desempenho da empresa e facilitar o acesso ao capital", surgindo a partir da teoria econômica tradicional 
para superar o chamado "conflito de agência", oriundo da separação entre a propriedade e a gestão empresarial.

Outra conceituação que pode aqui ser destacada nesse viés é definida pela Comissão sobre Governança Global (1996 apud GONÇALVES, 2005, p. 2):

Governança é a totalidade das diversas maneiras pelas quais os indivíduos e as instituições, públicas e privadas, administram seus problemas comuns. [...] Governança diz respeito não só a instituições e regimes formais autorizados a impor obediência, mas também a acordos informais que atendam aos interesses das pessoas e instituições.

Há, entre outros, um desafio à governança que diz respeito à sua legitimidade: se é construída a partir da participação crescente da sociedade civil global nas decisões e formulações estratégicas, é imprescindível que as organizações envolvidas tenham legitimidade. Este é um conceito subjetivo, caracterizado, segundo a teoria weberiana, como "parte da atitude do sujeito que legitima com respeito ao poder de legitimar, isto é, de uma 'crença', seja na validade do que é racional (segundo um valor ou propósito), na força da tradição ou na virtude do carisma" (BOBBIO, 1988, p. 172). Ou seja, a legitimidade é alimentada de maneira hierárquica, a partir dos que se encontram nas esferas mais baixas até as superiores, surgindo a partir da aceitação de que o poder conferido e exercido é apropriado, afirmando-se a ação decorrente como legítima.

Há, então, que atentar para o fato de que nem sempre que houver participação da sociedade civil haverá legitimidade democrática. Com a ampliação do conceito de governance, fica cada vez mais imprecisa sua diferenciação de "governabilidade" (SANTOS, 1997).

Já Melo (1995) e Diniz (1995) preferem direcionar o conceito de "governabilidade" às condições sistêmicas e institucionais sob as quais acontece o exercício do poder, destacando as características do sistema político: forma de governo, relações entre os Poderes e sistema de intermediação de interesses. Vale observar aqui que tanto na concepção "do conceito de governabilidade como na do de governance estão as concepções estrutural-funcionalistas de system capabilities e processo de conversão do sistema político, conforme amplamente utilizadas na literatura de modernização e desenvolvimento político" (SANTOS, 1997, p. 6). Adentra-se, ainda, na capacidade (capability) do sistema, ligada à sua performance como uma unidade em seu meio ambiente. 
Ainda, na perspectiva de Santos (1997), ao que parece, todas as tentativas utilizadas para analisar a governabilidade e crise de governabilidade (ou ingovernabilidade), ou de distinguir "governabilidade" e governance, remetem à origem estrutural-funcionalista da performance dos sistemas políticos. Por fim, pode-se pensar, então, "em governabilidade (ou capacidade governativa) como a capacidade de um sistema político de produzir políticas públicas que resolvam os problemas da sociedade", ou, ainda, como a capacidade de converter o potencial político de determinado "conjunto de instituições e práticas políticas em capacidade de definir, implementar e sustentar políticas" (SANTOS, 1997, p. 7).

É compreensível que a governança traga em seu histórico características do modelo de administração de empresas, que foi sendo adaptado e ajustado às necessidades das políticas públicas, marcado por uma crescente presença dos atores no cenário político e social, os quais vão se adequando às especificidades dos órgãos inseridos. São estas e outras características que assemelham a governança de uma escola à governança de uma empresa, principalmente no que se refere à implementação dessa proposta de gestão nas escolas estaduais de Santa Catarina.

Considerando, então, que o processo de eleição de gestores das escolas estaduais de Santa Catarina perpassa por esse novo modelo de governança, tendo como base a participação comunitária, a anunciada liberdade e autonomia da escola, sem deixar de ser um órgão público regido e mantido pelo Estado, faz-se necessário aqui estabelecer paralelo e diferenciação entre os conceitos voltados ao modo organizacional da escola, para que se possa compreender como surge e o que pretende a legislação que subsidia o processo eleitoral, requisitando a elaboração dos Planos de Gestão Escolar (PGEs) como critério de conhecimento e análise do candidato ao cargo. Esses mesmos conceitos, adiante, permitirão conhecer quais as propostas e concepções implícitas ou explícitas presentes nesses planos.

\section{DECRETO SC N. 1794/13, SOBRE GESTÃO ESCOLAR DA EDUCAÇÃO BÁSICA: IMPLANTAÇÃO DOS PLANOS DE GESTÃO ESCOLAR (PGES)}

Antes de se adentrar diretamente no decreto que implementa os PGEs, torna-se necessário apresentar a abordagem da Constituição de Santa Catarina acerca da educação, observando se, em seu texto, atualizado em fevereiro de 
2016, há alguma menção ao modelo de gestão implementado nas escolas do estado no ano de 2013.

Os escritos sobre a Educação, a Cultura e o Desporto compreendem o capítulo III da Constituição, iniciando-se pela seção I, da Educação. Em complemento ao que consta na Constituição Federal de 1988, o texto estadual reforça também os princípios de que a educação, direito de todos e dever do Estado, deverá ser ministrada com base nos ideais de igualdade, de liberdade, de solidariedade humana, de bem-estar social e da democracia, buscando o pleno exercício da cidadania (SANTA CATARINA, 2016).

Logo, em seu artigo 162, que apresenta os princípios segundo os quais a educação será ministrada, encontra-se, no inciso IV, o seguinte texto: “[...] gestão democrática do ensino público, adotado o sistema eletivo, mediante voto direto e secreto, para escolha dos dirigentes dos estabelecimentos de ensino, nos termos da lei; (revogada a expressão grifada pela EC n. 38)" (SANTA CATARINA, 1989 apud. SANTA CATARINA, 2016).

Com a alteração do texto da Constituição catarinense, o sistema eletivo, composto pelo voto direto e secreto, para escolha dos gestores das escolas, deixa de ser obrigatório e amparado pela legislação referência do estado. Contudo, no que segue ao seu texto, encontra-se o inciso IX - promoção da integração escola-comunidade (SANTA CATARINA, 1989 apud. SANTA CATARINA, 2016); ao se analisar esse princípio, recordam-se os conceitos de "governança" e "democracia", os quais fundamentam a participação social ativa da comunidade, estabelecendo uma relação entre os diferentes atores e setores.

Por meio do que havia sido estabelecido pela Constituição do estado, foi possível a implementação da Lei n. 16.794, de 14 de dezembro de 2015, que ativa o Plano Estadual de Educação (PEE) para o decênio 2015-2024. O Plano Estadual de Educação vem reforçar o que foi proposto pela Constituição anteriormente, enfatizando a promoção do princípio de gestão democrática da escola pública em sua meta 18.

Visando ao alcance da respectiva meta, foram estabelecidas 20 estratégias que conduzem ao cumprimento e implementação do texto proposto e condicionam desde a criação de políticas educacionais, conselhos, fóruns, até a garantia de participação da comunidade na organização escolar, fortalecimento de programas de formação continuada, implantação de mecanismos para avaliação institucional, 
comprometimento com a educação indígena, entre outros itens que objetivam alcançar a respectiva meta.

A partir do suporte obtido por meio da Constituição de Santa Catarina e do Plano Estadual de Educação, destaca-se, ainda, o Decreto SC n. 1794, de 15 de outubro de 2013, que dispõe sobre a gestão escolar da Educação Básica e cria os Planos de Gestão Escolar. Importante ressaltar que a versão utilizada do decreto teve seu texto alterado por outros decretos, como o de n. 1281, de 28 de agosto de 2017.

Logo em seu início, no que se refere às finalidades e aos princípios, encontra-se em seu artigo 1ㅇa gestão escolar democrática com vistas à autonomia escolar ${ }^{3}$. Em seguida, o artigo 2o apresenta em seu texto características do modelo de governança tratado anteriormente, quando se refere à transparência dos processos pedagógicos e administrativos ${ }^{4}$. Posteriormente, há o capítulo II discorrendo sobre a autonomia da escola, enfatizando a participação da comunidade escolar, sobretudo na elaboração do projeto político-pedagógico, envolvendo as relações sociais internas e externas, assim como as diferentes áreas de organização escolar.

O capítulo III, por sua vez, refere-se diretamente à gestão escolar ${ }^{5}$, mencionando em seu texto a observância das diretrizes e normas estabelecidas, bem como do Projeto Político-Pedagógico (PPP) e Plano de Gestão Escolar (PGE). No que segue, seu artigo 5 o trata mais detalhadamente a respeito da implementação dos PGEs:

Art. 5o O Plano de Gestão Escolar, para o período de 4 (quatro) anos, a iniciar no prazo de 12 (doze) meses após o final do mandato do Chefe do Poder Executivo, deverá explicitar metas que evidenciem o compromisso com o acesso, a permanência e o êxito na aprendizagem do estudante da Educação Básica e Profissional.

\footnotetext{
${ }^{3}$ Art. 1ํ A Gestão Escolar da Educação Básica e Profissional da rede estadual de ensino, em todos os níveis e modalidades, com a participação da comunidade escolar, tem por princípios a gestão democrática e a autonomia escolar (SANTA CATARINA, 2013, p. 1).

${ }^{4}$ Art. 2ㅇ A Gestão Escolar da Educação Básica e Profissional de que trata este Decreto tem por finalidade priorizar a qualidade educacional e promover a transparência dos processos pedagógico e administrativo (SANTA CATARINA, 2013, p. 1).

${ }^{5}$ Art. 4으 A gestão escolar será exercida pela equipe gestora integrada pelo diretor de escola e assessoria, com observância às diretrizes e normas oriundas da Secretaria de Estado da Educação (SED), da legislação educacional vigente, do PPP e do Plano de Gestão Escolar" (SANTA CATARINA, 2013, p. 1).
} 
$\S 1$ 을 Cabe à SED definir as dimensões e os elementos mínimos obrigatórios para o Plano de Gestão Escolar.

§2O O primeiro Plano de Gestão Escolarterávigência até31 de dezembro de 2015. §3ㅇ No período de transição deste processo, o primeiro Plano de Gestão Escolar será apresentado pelo atual diretor de escola e terá vigência até dezembro de 2015. (SANTA CATARINA, 2013, p. 2).

Destaca-se, nesse artigo acima, o período de vigência dos Planos de Gestão Escolar, assim como as metas que devem ser propostas com vistas ao acesso, à permanência e ao sucesso no processo de ensino-aprendizagem do educando. Coloca-se, ainda, sob responsabilidade da Secretaria de Estado da Educação (SED), a definição dos elementos mínimos que devem compor os planos. Nas questões referentes à avaliação e escolha dos PGEs, o artigo 60 apresenta:

Art. 60 O processo de escolha do Plano de Gestão Escolar, conforme previsto no art. 5o deste Decreto, será realizado em 2 (duas) etapas:

I - seleção pela banca avaliadora das propostas de Planos de Gestão escolar para submetê-los à escolha da comunidade escolar; e

II - escolha pela comunidade escolar, entre as propostas selecionadas pela banca avaliadora, do Plano de Gestão Escolar.

Parágrafo único. No processo de escolha, serão considerados os seguintes critérios de valoração por segmento representativo da comunidade escolar de que tratam os incisos II e III do art. 70 deste Decreto:

I - peso 2 (dois), relativamente à escolha dos pais ou responsáveis;

II - peso 1 (um), relativamente à escolha dos estudantes; e

III - peso 1 (um), relativamente à escolha dos profissionais da educação. (SANTA CATARINA, 2013, p. 2).

Por meio desse artigo, compreende-se como ocorre o processo de escolha do plano e a participação da comunidade escolar por meio do voto secreto no plano que melhor representar a realidade da escola e as propostas que a ela se destinam. É de função da SED, ainda, definir os critérios para composição da banca avaliadora, as competências para seleção dos planos e os procedimentos para apresentação e escolha das propostas.

Com algumas alterações dos incisos do artigo 90, seu texto final passou a ter de optar expressamente pelo regime de dedicação exclusiva e professor efetivo do quadro do magistério público estadual. Fica assim estabelecido:

I- ser professor, especialista em assuntos educacionais, assistente técnico pedagógico ou assistente de educação efetivo do Quadro do Magistério 
Público Estadual; (Redação alterada pelo Decreto N 1.281, de 2017). II- optar expressamente pelo regime de dedicação exclusiva, a ser ratificado no Termo de Compromisso de Gestão de que trata o § 20 do art. 11 deste Decreto, para ocupar a FG de diretor de escola; (Redação alterada pelo Decreto № 243, de 2015)

III- não ter sofrido, no exercício de função pública, penalidades disciplinares; IV - ter o estágio probatório homologado e publicado no Diário Oficial do Estado (DOE);

$\checkmark$ - estar em efetivo exercício na rede estadual de ensino;

VI- dispor de carga horária de 40 (quarenta) horas semanais de dedicação à escola; (Redação alterada pelo Decreto № 243, de 2015)

VII- comprovar a conclusão ou a matrícula em:

a) curso de formação continuada em gestão escolar, de no mínimo 200 (duzentas) horas, ofertado pela SED ou por instituição de ensino superior credenciada pela SED; ou

b) curso de pós-graduação lato sensu em gestão escolar, ofertado por instituição de ensino superior autorizada pelo Ministério da Educação (MEC) ou pelo Conselho Nacional de Educação (CNE); (Redação alterada pelo Decreto № 284, de 2015)

VIII - Não possuir mais de 5 (cinco) faltas injustificadas nos 3 (três) anos anteriores à inscrição do Plano de Gestão Escolar; (Incluído pelo Decreto № 307, de 2015)

IX- não ter sido destituído da função de diretor; e (Incluído pelo Decreto № 243, de 2015)

X- ter concluído o transcurso de 12 (doze) meses a partir da remoção, exceto o servidor que participou de processo de reordenamento, em razão de extinção ou criação de unidade escolar ou em razão de alteração do número de turmas, que importe em redução do número de aulas; (Redação alterada pelo Decreto № 1.281, de 2017)

$\mathrm{XI}$ - não se encontrar na condição de readaptado. (Redação alterada pelo Decreto № 359, de 2015). (SANTA CATARINA, 2013, p. 3-4).

Considerando as exigências expostas no artigo e seus respetivos incisos, poderá haver uma redução significativa no número de candidatos inscritos no processo de escolha de gestores. Há, desse modo, o primeiro método de seleção de candidatos no que se refere ao cumprimento dos critérios de participação estabelecidos pela legislação.

Aqueles que passarem por essa primeira etapa de inserção nos requisitos propostos deverão, ainda, optar por apenas uma escola para inscrever seu Plano de Gestão ao processo de escolha, justificando junto à sua comunidade escolar 
a intenção em assumir a Função Gratificada (FG) de gestor escolar em outra unidade que não a sua, esclarecendo a possibilidade de ser substituído por outro profissional.

Poderá ainda ocorrer, conforme previsto no decreto, de não haver planos apresentados em algumas instituições escolares, ou mesmo de haver somente um e esse não ser escolhido pela comunidade escolar. Nesses casos, estabelece-se a legislação:

Art. 10. Cabe ao titular da SED a designação do diretor de escola, em conformidade com os requisitos de que tratam os incisos I, II, III, IV, V, VI, VIII, IX, X e XI do caput do art. 9o deste Decreto, até a edição de novo processo de consulta à comunidade escolar, nas seguintes hipóteses: (Redação alterada pelo Decreto № 1.281, de 2017) I- não havendo proposta de Plano de Gestão escolar; e

II- quando a comunidade não referendar o Plano de Gestão Escolar que Ihe for apresentado. (SANTA CATARINA, 2013, p. 5).

Por fim, quando o gestor escolar for escolhido, “[...] firmará Termo de Compromisso de Gestão com a SED, elaborado com base no Plano de Gestão Escolar. (Redação alterada pelo Decreto N. 243, de 2015)". Ele será "acompanhado e avaliado anualmente pela SED, ouvida a Gerência de Educação (GERED) da Secretaria de Estado de Desenvolvimento Regional (SDR) e o Conselho Deliberativo Escolar" (SANTA CATARINA, 2013, p. 6).

Os gestores que já estavam em exercício durante a publicação do decreto tiveram um prazo de 150 dias para postar seus planos e permanecer no cargo até 31 de dezembro de 2015. Passado o prazo estabelecido, "sem a apresentação do primeiro Plano de Gestão Escolar pelo atual diretor de escola, observou-se o disposto no art. 10 deste Decreto" (SANTA CATARINA, 2013, p. 7). Em posse do cargo, conforme artigo 16ㅇ, "A vacância da função de diretor de escola se dará por: I - conclusão da gestão escolar; II - renúncia; III - destituição; IV - aposentadoria; ou V-morte" (SANTA CATARINA, 2013, p. 7).

Depois de delimitados os critérios para o processo de eleição dos gestores das escolas estaduais de SC, deparou-se com muitas restrições, o que torna a escolha de gestores restritiva a um número menor de candidatos, em razão dos critérios para candidatura. Além de delimitar o processo a muitos critérios de exclusão, a proposta, que busca conduzir a uma gestão democrática, reflete uma prática já efetivada de administração escolar. 
Trata-se de um processo que ainda se encontra em estruturação na busca pela democratização da gestão escolar, mas que já passou por alterações em seus documentos e decretos, fazendo com que a escolha dos gestores seja facultativa e não condicionada por meio de eleições.

\section{CONSIDERAÇÕES}

A gestão escolar democrática vem ganhando forte destaque em meio a estudos e discussões desde a década de 1990, resultando em uma nova relação estabelecida entre o Estado e as políticas públicas. Dessa relação, foram emergindo novos conceitos e formas de gestão, aliados às políticas públicas, sobretudo as educacionais. Um exemplo dessas políticas que foram se modificando ao longo do tempo, a fim de contemplar algumas necessidades que surgiam, diz respeito à reestruturação da gestão escolar, apresentada aqui pelo processo de implementação do modelo de governança conduzindo à eleição de gestores nas escolas estaduais de SC.

Essa democracia buscada pelas instituições escolares é, segundo Bastos (2001), à sociedade e aos trabalhadores em educação, vista como único caminho à reconstrução da escola pública de qualidade. Dessa maneira, destaca-se que, teoricamente, o caminho para a democratização da gestão já está proposto, conforme se observa por meio das legislações implementadas a partir da Constituição de 1988. O referencial teórico que subsidia esse processo também é vasto e norteia as questões centrais para o caminho da nova governança, destacando conceitos como participação, autonomia e descentralização no modo de gerir a educação.

Porém, conforme constatado no respectivo estudo, o papel ideológico presente nesse modelo de governança torna explícito que a descentralização está operando como campo não de deliberação, mas de execução daquilo que foi decidido pelos poderes centrais da educação. Em consequência, a autonomia da escola fica restrita a poder decidir apenas sobre a execução e algumas questões superficiais, enfraquecendo seu poder de mudança.

A democracia da escola, nesse caso, está longe de promover a qualidade cidadã do ensino, expressando a contradição presente no processo de institucionalização da gestão democrática escolar. Na busca pela modernização da gestão da escola pública, muitas propostas acabam por condicioná-la ao fundamento da 
gestão gerencial, desempenhada pelo diretor da escola, delimitando hierarquias e condicionando a participação dos envolvidos a determinados interesses. O Estado, por sua vez, permanece pensando a educação com agentes externos (empresas; bancos; multinacionais), assim, o currículo e a organização escolar, de modo geral, não são pensados por quem vive o dia a dia da prática escolar.

\section{REFERÊNCIAS}

BASTOS, João Baptista. Gestão democrática da educação: as práticas administrativas compartilhadas. In: BASTOS, João Baptista (Org.). Gestão democrática. Rio de Janeiro: DP\&A Editora, 2001. p. 7-30.

BOBBIO, Norberto. A Teoria do Estado e do Poder. In: BOBBIO, Norberto. Ensaios Escolhidos. São Paulo: C.H. Cardim, 1988. p. 157-8.

COMISSÃO SOBRE GOVERNANÇA GLOBAL. Nossa Comunidade Global. O Relatório da Comissão sobre Governança Global. Rio de Janeiro: FGV, 1996.

DINIZ, Eli. Governabilidade, democracia e reforma do Estado: os desafios da construção de uma nova ordem no Brasil dos anos 90. Revista de Ciências Sociais, Rio de Janeiro, v. 38, n. 3, p. 385-415, 1995.

FREIRE, Paulo. A educação na cidade. São Paulo: Paz e Terra, 1991.

FREIRE, Paulo. Educação como prática de liberdade. 23. ed. Rio de Janeiro: Paz e Terra, 1967.

GONÇALVES, Alcindo. O conceito de governança. In: CONGRESSO DO CONSELHO NACIONAL DE PESQUISA E PÓS-GRADUAÇÃO EM DIREITO [CONPEDI], 14., 3-5 nov., 2005, Fortaleza. Anais [...]. Manaus: CONPEDI, 2005. p. 1-16. Disponível em: http://www.publicadireito. com.br/conpedi/manaus/arquivos/anais/XIVCongresso/078.pdf. Acesso em: 12 mar. 2018.

LIMA, L. C. Organização escolar e democracia radical. São Paulo: Cortez, 2000.

LOURENÇO, Fábio; MOREIRA, José Manuel. A Lógica da Governance -Governação/ Governança - nas Políticas Públicas de Turismo. Revista Gestão e Políticas Públicas, São Paulo, v. 4, n. 1, p. 22-44, 2014. Disponível em: http://www.revistas.usp.br/rgpp/article/ view/114309. Acesso em: 27 maio 2018.

MALLOY, J. Política econômica e o problema da governabilidade democrática nos Andes Centrais. In: SOLA, L. (Org.). Estado, mercado e democracia. São Paulo: Paz e Terra, 1993. 
MELO, Marcus André B. C. de. Ingovernabilidade: Desagregando o argumento. In: VALLADARES, L. (Org.). Governabilidade e pobreza. Rio de Janeiro: Civilização Brasileira, 1995.

NOGUEIRA, Marco Aurélio. Em defesa da política. São Paulo: Senac, 2001.

REIS, Fábio Wanderley. Governabilidade, instituições e partidos. Novos Estudos Cebrap, São Paulo, v. 1, n. 41, p. 40-59, mar. 1995.

ROSENAU, James N. Governança, ordem e transformação na política mundial. In: ROSENAU, James N; CZEMPIEL, Ernst-Otto. Governança sem governo: ordem e transformação na política mundial. Brasília: Universidade de Brasília, 2000, p. 11-46.; São Paulo: Imprensa Oficial do Estado, 2000. p. 11-46.

SANTA CATARINA (Estado). Constituição (1989). Constituição do Estado de Santa Catarina. Edição atualizada com 71 Emendas Constitucionais. Florianópolis: Assembleia Legislativa, 2016. 177 p.

SANTA CATARINA (Estado). Lei n. 16.794, de 14 de dezembro de 2015. Ativa o Plano Estadual de Educação (PEE) para o decênio 2015-2024. Florianópolis, SC, 2015.

SANTA CATARINA (Estado). Decreto n. 1794/13, 16 de outubro de 2013. Dispõe sobre a gestão escolar da Educação Básica e profissional da rede estadual de ensino, em todos os níveis e modalidades. Diário Oficial n. 19.683, Florianópolis, 16 out. 2013.

SANTOS, Maria Helena de Castro. Governabilidade, governança e democracia: criação da capacidade governativa e relações executivo-legislativo no Brasil pós-constituinte. Revista de Ciências Sociais, Rio de Janeiro, v. 40, n. 3, p. 335-76, 1997.

WEFFORT, Francisco. Correia. O populismo na política brasileira. In: FURTADO, Celso. (Org.). Brasil: Tempos Modernos. Rio de Janeiro: Paz e Terra, 1967.

WORLD, Bank. Governance and Development. Washington, D.C, 1992.

\section{Sobre os autores:}

Aline da Silva Serpa Marangoni: Doutoranda na Educação pela Universidade do Vale do Rio dos Sinos. Mestrado e licenciatura em Educação pela Universidade Federal da Fronteira Sul. Coordenadora pedagógica na rede municipal de educação de Chapecó, Santa Catarina. E-mail: alinesilvaserpa@hotmail.com, Orcid: http://orcid.org/0000-0001-6073-8144 
Oto João Petry: Graduação em Pós-Doutorado em Educação pela Universidade Regional Integrada do Alto Uruguai-Rio Grande do Sul. Doutorado e mestrado em Educação pela Pontifícia Universidade Católica do Rio Grande do Sul. Licenciatura em Pedagogia e em Estudos Sociais pela Fundação Universitária do Desenvolvimento do Oeste. Professor da Graduação e Pós-Graduação da Universidade Federal da Fronteira Sul.E-mail: oto.petry@uffs.edu.br, Orcid: http://orcid.org/0000-0001-9216-5301

Recebido em: 27/03/2020

Aprovado em: 31/01/2021 